the loss of power being alsolute in all the muscles of the left shoulder and arm, the fingers alone showing any power of movement, and that very feebly. No loss of power in the lower extremities, but some weakness of the back complained of, and pain on moving the neck. No affection of sphincters. Pupils normal. Temperature $100^{\circ}$. Pulse 61 , fairly full. Urine acid; no albumen.

2 lst.-Tingling and hyperiesthesia less marked. Some improvement in motor power of the right arm, especially in the flexors of the forearm, wrist, and fingers. No improvement in the left arm. Grasp of hands, as measured by dynamometer: right hand, $15 \mathrm{lb}$; ; left, $8 \mathrm{lb}$. Temperature normal.

23rd.--Slight improvement in motor power. Grasp of right hand, $18 \frac{1}{2} \mathrm{lb}$; left, $10 \mathrm{lb}$. No wasting of muscles detected. Still some tingling in both arms, especially the left; and hyperæesthesia over the left shoulder joint and supraclavicular region.

24th.-A blister was applied to the left side of the neck and shoulder over the region of the brachial plexus.

27th.-Distinct increase of motor power, especially in the right arm, with which he can now feed himself. Grasp of right hand, $25 \mathrm{lb}$.; left, $15 \mathrm{lb}$. Can now raise the left hand and forearm slightly from the bed. Less pain in the shoulder. No hyperæesthesia.

3Ist.-Grasp of right hand, $30 \mathrm{lb}$; ; left, 18 lb. Still has some tingling in both arms on attempting to move them, most marked in the left. Still some weakness of back, so that he cannot sit up in bed unsupported.

Sept. 3rd.-Grasp of right hand, $32 \mathrm{lb}$.; left, $15 \mathrm{lb}$. Right arm stronger, but left apparently weaker than when last noted. No hyperresthesia. Slight pain in the left shoulder when it is moved. Is able to sit up in bed. The muscles of both arms are flaccid and appear to be wasted, as the skin is loose and wrinkled. Circumferential measurement of arms $8 \mathrm{in}$. above the styloid process of radius : right, $10 \frac{1}{4}$ in.; left, $9 \frac{1}{3}$ in.

10th.-Circunferential measurements the same as on Sept. 3rd. Grasp of right hand, $40 \mathrm{lb}$; left, $20 \mathrm{lb}$. No hyperresthesia. No tingling sensations, but occasional pains of neuralgic character down both arms, more marked in the left, and never simultaneously in both arms.

11th.--The constant current from twenty cells was applied for ten minutes - the positive pole at the nape of the neck and the negative pole in the left hand; and the interrupted current for ten minutes to the muscles of the arm and forearm, which were very flaccid and certainly wasted.

13th.-General improvement. Battery applied as abovenoted daily. Can now lift the left hand to the head. Grasp of right hand, $48 \mathrm{lb}$.; left, $18 \mathrm{lb}$. Able to dress himself, and sot up for the first time. Subjective sensations as noted above, especially in the left arm; but no tenderness over the shoulder. Some tenderness on pressure over the museles of both upper extremities, but especially the left. The muscles of the left arm feel very flaccid and wasted, but the circumferential measurements are practically the same as when last noted.

From this date till his discharge on Sept. 16th, the improvement continued steadily. He was ordered to attend as an out-patient.

Remarkis by Mr. Clutton. - This patient was seen in the out-patient room on Nor. 9th, and was found to have steadily improved. He could raise both arms and perform all the natural movements of which the upper extremities are capable, but on the left side these movements were all distinctly feeble and wanting in power and precision, whilst on the right they appeared to have regained their former condition. The case would appear to be one of hæemorrhage within the vertebral canal, and most probably between the theca and cervical vertebra. The cord itself must have been uninjured, as conduction was perfect to all parts below the brachial plexus. The absence of any external lesion and the bilateral nature of the paralysis render it extremely probable that the hæmorrhage was within the canal. The diaphragm was unaffected, whilst the shoulder muscles were paralysed, a condition which suggests that the upper limit of the extravasation was between the fourth and fifth cervical vertebræ, and the fingers being movable would, I imagine, place the lower linit at or about the junction of the last cervical with the first dorsal vertebra. It is, I think, unlikely that the hremorrhage was within the membranes, as such a condition is rare, and would have probably caused compression of the cord itself as well of the nerves given off in that position. The blood would also be more likely to diffuse itself over a larrer area. The only symptom of any irritation was the presence of hyperesthesia over the neck and shoulder and down the left arm. The absence of any post-nortem examination renders the case inconclusive, but the symmetrical character of the paralysis and the patient's recovery make it one of considerable interest.

CASE 2. (Under the care of Mr. Makins.)-J. G. Caged forty-seven, a sawdustman, was adnitted on Aug. 3lst, 1888, into the Clayton ward. Previous history unimportant. While driving with a cartload of sawdust he slipped off the cart, and fell, according to his own account, on to his left shoulder (a man who was with him says he fell on to the top of his head). He was nneonscious for a few minutes only, and when brought to the hospital about an hour after the accident was found to be quite conscious; had not vomited, and had no symptoms of cerebral injury, or sign of injury to the cranium or cervical spine. The right pupil was slightly larger than the left, but both acted to light and accommodation. Both arms were paralysed from the shoulder muscles downwards (excepting the pectorals and trapezius), but there was no affection of sensation in either arm. Some tenderness was complained of over the left side of the neck and in the shoulder joint, and pain (subjective) down the arm, but there was no swelling or other sign of local injury, and no affection of legs, trur.k nuuscles, or sphincters.

On Sept. lst the right arm appeared to have recovered power, being as strong as ever according to the statement of the patient. The left arm could be moved to some extent at the shoulder by action of the pectorals and trapezius muscles, but was completely paralysed below the shoulder joint, no particular groups of museles being singled out. No anresthesia or hyperæesthesia, but subjective pain from shoulder downward into fingers, most marked when the limb is passively moved. No improvement in motor power took place during the first ten days, and slight wasting of the nuuscles (estimated by circumferential measurements) occurred, flaccidity being very marked. The wasting appeared not to single ont any groups of muscles, but to affect all equally. Subjective sensations of pain were occasionally complained of, especially during the first two or three days. No affection of any other part of the body; temperature normal ; general health good. On the tenth day (Sept. 9th) a blister was applied to the left side of the neck, over the region of the brachial plexus. No obvious change was observed till about the eighteenth or nineteenth day, when slight return of power was noticed, first in the flexors of the fingers, then in those of the forearm, and then in the extensors, so that by the twentieth day he could hold the hands out extended at the wrist for a few minutes. On the twentieth day he was discharged to attend as an outpatient, to have the constant current for ten minutes from thenape of the neck to the fingers applied daily, with faradism of the affected muscles. Since leaving the hospital slow improvement has taken place, so that he has now (Nov, 10th) recovered power to a considerable extent in all the muscles except the deltoid, which is still very flaccid and almost powerless. The patient has attended very irregularly, usually only about twice a week, so the regular application of the battery has been impossible.

Remarks.-. The above case scarcely requires separate comment, being almost identical with No. 1. The patient in Case 2, as compared with the other man, was markedly inferior, both in mental and bodily activity; this, on the one hand, rendered an investigation of subjective symptoms difficult and unsatisfactory, and, on the other, may have accounted for the slower rate of improvement.

\section{BOLTON INFIRMARY AND DISPENSARY.}

\section{CARCINOMA OF GALL BLADDER; NECROPSY ; REMARKS.}

(Under the care of Mr. Garstang.)

The following case was reported by Dr. Peter Yates.

Thomas $\mathrm{N}-$, aged forty-five years, was admitted on Sept. 18th, 1888, suffering from well-marked icterus and swelling of the abdomen. The following history was adduced. The patient was quite well up to May lst, when it was noticed by his friends that his skin was becoming yellowish in colour. A local medical man was consulted, and medicine was prescribed. The discolouration, however, gradually got deeper, and two months before admission it 
was noticed that his abdomen was gradually swelling. During the whole of this period there was no pain attending either the jaundice or the swelling. Three weeks before admission he first felt pain in the epigastrium, and this had a distinct relation to the ingestion of food, following and remaining for about thrce hours after eating. The bowels have always been costive. No history of hepatic colic. Previously to the onset of the present illness he had always been a healthy man, except occasionally suffering from "bile in the stomach." Has always been temperate, only taking an occasional glass of beer to meals. No history of syphilis. Family history good.

On admission, the slin and ocular conjunctive were intensely yellow, and there was great discomfort from itchiness of the skin. Pulse regular and fairly strong, 64 per minute. Temperature normal. Abdomen ascitic, measuring at the level of the umbilicus thirty-two inches. Liver dulness in right mammary line fiveinches and a quarter. Palpation of the abdomen was impossible on account of the ascites. No pain or tenderness on pressing over the region of the liver. Heart sounds normal. No abnormal physical signs in chest. The stools clayey, almost white. Urine of a dark reddish-brown colour; sp. gr. 1020; of an acid reaction; no albumen, but giving a well-marked reaction with nitric acid for bile pigments. Calomel and colocynth were ordered as pills to be taken twice a day, and to have a low diet of milk and beef-tea.

Sept. 25th. -Feels better. Pain in epigastrium after food not nearly so frequent or well marked. Abdomen still tense, and the patient complains of considerable amount of flatus after food. Ascites increasing.

Oct. 3ril- - Un account of the great increase of the ascitic Huid, which had begum to impede respiration, paracentesis abdominis was performed, about seven pints and a half of deeply stained fluid being withdrawn. On palpating the abdomen almost immediately after the withdrawal of the fluid, the thinned-out border of the left lobe of the liver could be easily felt, but the edge of the right lobe could not be detected beneath the costal margin. On deeply palpating the abdomen in the umbilical and lumbar regions a few indistinct nodular masses could be felt.

Oct. 4th.- Has been much relieved and feels much more comfortable since the tapping. Slept soundly during the night.

5th.- Vomited freely during the night, the romit being of a darkish-brown colour, with a characteristic " coffeegrounds" appearance. Has also suffered greatly from hiccough, which comes on about ten minutes before the vomiting, after which it disappears. Does not complain of any pain or tenderness. Turpentine capsules were ordered by the mouth, and nutrient enemata every four hours.

6 th. The vomiting still continues, preceded by the hiccough, which has become very distressing. Ergotine, hypodermically and as pills, had no effect. Ice was ordered to be constantly sucked, and ice-bags applied to the epigastrium, but withont diminution in the vomiting. The vomit examined microscopically was found to be composed of
mucus and broken-down and partially digestcd blood corpuscles, but no sarcinie.

The patient gradually got weaker from the constant loss of blood and exhaustion from hiccough and vomiting. He died at 7 o'clock next morning.

At the necropsy, made twenty-eight hours after death, a considerable quantity of bile-stained Huid was found in the peritoneal cavity, and scattered freely over the surface of the parietal peritoneum and mesentery were a number of nodular growths about the size of horse-beans. The ascending colon was firmly adherent to the parietes, and unilerneath the upper part of the duodenum, pylorus, liver, right kidney, and head of the pancreas were all firmly matted together: The gall bladder, owing to this matted condition, could not be made ont at all, but, on section of the whole mass, a cavity, which represented the gall bladder, was found, filled witl twenty-six small irregular gall stones, varying in size from a lentil to a split pea. There was also cuntained in this cavity a considerable quantity of thick pale mucus. In the drict beyond was found a much larger gall stone, tightly impacted, and surrounding this a mass of new growth, linding down all the surrounding organs. The liver tissue was apparently healthy, but deeply discoloured, all the bile ducts being much dilated. Scattered throughout the substance of the liver were a number of small nodular growths, especially on its upper surface, and the diaphragmatic peritoneun was also freely studded with similar growths. The kilneys were considerably disorganised, the cortex being much thickened, and the Malphigian pyramills contracted. The new growth had involved the fat at the back of the right kidney, which was adlierent to the capsule. The body of the pancreas was henlthy, but the hear was involved in the growth. The stomach and duofenum were congested, but no ulceration or ruptured vessel could be discovered. The pylorus was very little, if at all, constricted although surrounded by the growth. Other organs healthy. Portions of the above growtlss were sectionised, and found, under the microscope, to be carcinoma of a scirrlous nature. The liver in the neighbourhood of the gall bladler wass gradually becoming invaded, as also the capsulo of the right kidney.

Remcerks. - Primary carcinoma of the gall ducts and gall bladder is sonetimes met with, but the point of interest in this case is the probable deternining cause of the growth. The impaction of the large gall stone in the commencement of the common bile duct nost likely in the first place set up a simple inflammatory process, which afterwards took on a cancerous action, rapidly growing and involving the neighbouring organs. Other points of interest are the absence during life of any symptons of impaction, there being no hepatic colic, and the rapidity of the case to a fatal termination from the onset of the synptoms.

\section{KASHMIR MISSION HOSPITAL. ABDOMNAL C.ASES.}

(Under the care of Mr. A. Neve and Dr. E. F. NEve.)

C.ASE 1. Ovarian cyst; ovariotomy; rccovery. - Raged about thirty-five, with typical ovarian tumour physiognomy. The swelling was first observed ten months previously to admission. The abiomen was very large, measuring thirty-eight inches in circumference, and was entirely filled by a regular, fluctuating tumour, not movalie. Diagnosis : a cyst, chiefly unilocular, of left ovary.

Operation. - Chloroform having been administered, a fourinch incision was made, the omental adhesions were separated and ligratured, and the cyst was tapped. No more adhesions being found, the tumour was drawn out. The pedicle, which was long and not thick, was ligatured after transfixion, and each half tied, with one encircling linot added. The abdomen was then irrigated with warm water which had been previonsly boiled. A little oozing took place apparently from the omentum. The pelris was sponged till dry, a glass drainage tube inserted, and stitched with silk in the usual manner. Examination of the tumour showed it to be a multilocular cyst with very varied contents. The evening temperature was $101 \cdot 3^{3}$; aftes this convalescence was afebrile.

The discharge was for two days blood stained; on the third day it was clear, and only a teaspoonful in amount. On the fourth evening the tube was removed. The first dressing was on the seventh day, when the wound was found healed and the stitches were reniuved. For several days there were a few drops of discharge from the sinus left after the removal of the drainagre tube. At the end of the third week she sat up, and was out. She went home on the twenty-sixth day, looking years younger than before the operation.

Remarks by Mr. A. NEYus.-The preparations for the operation were those of strict Listerism, the operation itself being aseptic rather than antiseptic. The drainage tube did no harm, and may have been useful. I was much indebterl to Miss L. Butler, who superintended the nursing, and assisted in the operation.

CASE 2. Suppurating orarian cyst; tapping; injection; cure.-The patient, a well-to-do woman, had a tumour filling the left side of the pelvis, projecting to the level of the unbilieas. It was noticed three months previously; latterly it had been painful, and she was getting weak. Diagnosis : probably an ovarian cyst.

I'reatment.-An exploratory incision or any attempt to excise was refused by the friends. On aspirating, some very fetid pus was withdrawn, but the tumour was only reduced by one-half. At intervals of a fortnight four aspirations were performed ; after each it rapidly refilled. A small incision was made, and the peritoneal surface at the seat of the punctures exposed and allowed to granulate for a week; the cyst was again aspirated and one drachm of pure carbolic iodine injected. There was pain for a few days. The tumour then began to diminish, and the patient six months later was quite well. 